\title{
Differences between autogenous and reactive obsessions in terms of metacognitions and automatic thoughts
}

This article was published in the following Dove Press journal:

Neuropsychiatric Disease and Treatment

\author{
İlkay Keleș Altun' \\ Emel Uysal ${ }^{2}$ \\ Evrim Özkorumak \\ Karagüzel $^{2}$ \\ 'Department of Psychiatry, Kanuni \\ Research and Training Hospital, \\ Trabzon, ${ }^{2}$ Department of Psychiatry, \\ Karadeniz Technical University, \\ Trabzon, Turkey
}

Background: Obsessive compulsive disorder (OCD) is characterized by obsessions and compulsions. Obsessions have been classified as autogenous obsessions and reactive obsessions on the basis of the cognitive theory of Lee and Kwon. The aim of this study was to investigate the differences between autogenous groups (AG) and reactive groups (RG) in terms of metacognition and automatic thoughts, for the purpose of investigating the differences of cognitive appraisals. Methods: One hundred and thirty-three patients diagnosed with OCD were included in the study as the patient group. A control group was formed of 133 age, gender and education-matched healthy individuals. The OCD group patients were separated into subgroups according to the primary obsessions. The sociodemographic data, and the Yale-Brown Obsessive Compulsive Scale, Metacognition Questionnaire-30 (MCQ-30), Automatic Thoughts Questionnaire (ATQ), Beck Depression Inventory (BDI) and Beck Anxiety Inventory (BAI) scores of the AG, RG, and control groups were compared.

Results: The MCQ-30 (total) and the subscales of MCQ-30 and ATQ scale points were seen to be significantly higher in the AG than in the RG and significantly higher in the RG than in the control group. In the reactive obsession group, the predictive variables of the ATQ points were determined to be MCQ-30 (total), BDI and BAI. In the autogenous obsession group, the predictive variables of the ATQ points were determined to be BDI and BAI.

Conclusion: In the current study, differences were determined between the AG and the RG in respect of metacognitions and automatic thoughts. In light of these results, the recommended grouping can be considered useful in the identification of OCD sub-types. There is a need for further studies to identify more homogenous sub-types of OCD. Future multi-centered studies of sub-typing with larger samples using more specific instruments to sub-type and dimensional evaluation will be useful for detailed evaluation and better understanding of the subject.

Keywords: obsessive compulsive disorder, autogenous, reactive, obsessions, metacognitions, automatic thoughts

\section{Introduction}

Obsessive compulsive disorder (OCD) is characterized by obsessions, defined as egodystonic, repeated and unwanted thoughts, impulses or images, revealing anxiety and discomfort, and secondary to those, compulsions that are defined as involuntary repeated behaviors or mental rituals. ${ }^{1}$

OCD is heterogenous in respect of clinical characteristics and studies have been conducted more directed to defining sub-types with homogenous characteristics. In this context, obsessions have been classified as autogenous obsessions and reactive obsessions on the basis of the cognitive theory of Lee and Kwon. ${ }^{2}$ 
Autogenous obsessions, which are more repeated and create more anxiety, are obsessions that are less mentioned and occur with less stimulation but can arouse more discomfort in the individual. Aggression and religious and sexual obsessions are in this group. Reactive obsessions tend to occur more with an external trigger, are thought to be less absurd by the individual and therefore there is a lesser need felt to hide them and these are obsessions that cause less discomfort compared with others. Contamination, doubt, symmetry and ordering and hoarding obsessions are in this group. ${ }^{2}$

Metacognitions, defined as "cognitions about cognitions" or thinking about thoughts, consider the process of thought, including strategies for observation, regulation and control and knowledge and beliefs related to the process. ${ }^{3}$ In other words, metacognition is the dimension that observes, interprets, evaluates and regulates processes within the knowledge processing system itself. ${ }^{4}$

According to the metacognitive model for OCD, known as the Self-Regulatory Executive Function, the reasons for negative interpretations of obsessive beliefs are the metacognitive beliefs related to the meaning of having these thoughts and dangerous results. ${ }^{5}$ In the metacognitive model of OCD, beliefs about the meaning of thoughts and beliefs related to the necessity of controlling the thought form the basic areas of thought. In beliefs related to the meaning of the thought, while there are cognitive errors such as thought-action fusion, thought-event fusion and thought-object fusion, there are also beliefs related to the necessity of controlling thoughts or ritualistic behaviors performed for the purpose of eliminating unwanted results of the obsessive thought. ${ }^{6}$

According to cognitive theory, the cognitive structure has 3 main components. On the surface, there are automatic thoughts within the daily mental flow of an individual. When interviewing depressive patients, some negative, involuntary thoughts that occurred rapidly and repetitively with changes in emotion were defined as automatic thoughts by Beck and these were said to resemble reflexes. ${ }^{7}$ According to Beck, the reason for different automatic thoughts to the same stimulus in different people and different forms of automatic thoughts in the same person at different times, was the basic beliefs of the individual. Compared with healthy individuals, the automatic thoughts of those with a psychological disorder are more rapid, rigid and flawed. Automatic thoughts are the reason for the continuation of the pathology. ${ }^{8}$

The aim of this study was to investigate the differences between autogenous and reactive groups (AG and $R G$ ) in terms of metacognition and automatic thoughts, for the purpose of investigating the differences of cognitive appraisals between these two groups and compare the sociodemographic differences between them. The basic hypothesis of the study when considering the source of obsessions is AG and RG show significant differences in terms of metacognition and automatic thoughts, and the patients with autogenous obsessions have a higher score of negative automatic thoughts and metacognition scale.

As a result of the studies by Lee and Kwon ${ }^{2}$ and factor analyses, this discrimination (autogenous vs reactive) can make pathophysiological mechanisms more understandable and investigating the differences of cognitive appraisals between these two groups may give new information for increasing the efficacy of cognitive-behavioral, metacognitive and pharmacologic interventions.

\section{Method}

The data of this cross-sectional descriptive study were collected between March 2014 and December 2015. The study group comprised patients diagnosed with OCD who presented at the Psychiatry Outpatient Clinic of Karadeniz Technical University Medical Faculty, who met the inclusion criteria and agreed to participate in the study. A control group of healthy individuals was formed. Written informed consent was obtained from all the study participants.

Exclusion criteria were illiteracy, mental retardation, age $<18$ or $>65$ years, dementia or other organic mental disorder, head trauma, epilepsy or other major neurological disorder, alcohol or substance abuse, or any Axis-I comorbid disease. Approval for the study was granted by the Clinical Research Ethics Committee of Karadeniz Technical University with decision no: 2014/6, dated 21.03.14.

Between March 2014 and December 2015, a total of 308 patients were diagnosed with OCD at the Psychiatry Outpatient Clinic of Karadeniz Technical University Medical Faculty. Of these, 43 did not wish to participate in the study, 2 were aged $>65$ years and $4<18$ years and 3 were illiterate. A co-diagnosis of major depressive disorder was made in 39 patients, other anxiety disorders in 31, psychotic disorder in 23, bipolar disorder in 11, mental retardation in 3, alcohol abuse in 1, epilepsy in 3 and an intracranial mass in 1 . These patients were excluded from the study. A further 11 patients were excluded; 3 patients did not complete the tests and in 8 patients, decision could not be made for primary obsession as they had both autogenous and reactive obsessions when scanned with the Yale-Brown Obsessive Compulsive Scale (Y-BOCS). The remaining 133 patients diagnosed with OCD were included in the study as the patient group. A control group was formed of 133 age, gender and education-matched 
healthy individuals. The OCD group patients were separated into sub-groups according to the primary obsessions. In accordance with the diagnostic criteria reported by Lee and Kwon ${ }^{2}$ that related to the content of primary obsessions and the content of the associated compulsions in the evaluation made with the Y-BOCS symptom check list, Patients with one or more of the following as primary obsessions: aggression religious or sexual obsessions, were included in the autogenous group (AG). ${ }^{2}$ Patients with one or more of the following as primary obsessions: contamination, doubt, symmetry or hoarding, were included in the RG. Patients were excluded if a decision could not be made for primary obsession as they had both autogenous and reactive obsessions when scanned with the Y-BOCS symptom check list. Although the obsession type of doubt is not included in the Y-BOCS symptom list, it was included in the evaluation as findings were seen in this study. Of the 133 OCD patients, 59 were classified as autogenous and 74 as reactive. The control group of 133 age, gender and education-matched healthy individuals was formed of volunteers from hospital staff, university students and those in the close environment. The sample size of the study was calculated with power analysis according to Moritz et al. ${ }^{9}$ According to our analysis, 70 people in each group would correspond to $90 \%$ power. It reached 59 people for $\mathrm{AG}$ and 74 people for $\mathrm{RG}$.

A sociodemographic form, the Structured Clinical Interview for Diagnostic and Statistical Manual of Mental Disorders, Fourth Edition (DSM-IV) (Structured Clinical Interview for DSM-IV Axis I Disorders [SCID-1]), the Y-BOCS and Symptom Control List, the Metacognition Questionnaire-30 (MCQ-30), the Automatic Thoughts Questionnaire (ATQ), the Beck Depression Inventory (BDI), and the Beck Anxiety Inventory (BAI) were administered to all the participants in Turkish. The sociodemographic data, and the Y-BOCS, MCQ, ATQ, BDI and BAI scores of the $\mathrm{AG}, \mathrm{RG}$ and control groups were compared.

\section{Data collection tools}

\section{Sociodemographic data form}

The form included age, gender, marital status, family history, age at onset of disease, duration of disease, duration of treatment and other states that could be related to OCD.

\section{SCID-I}

This was developed by First et al. ${ }^{10}$ It was developed as a systematic way of questioning symptoms to increase the validity of diagnoses by facilitating the scanning of the DSM-IV diagnostic criteria. Studies for reliability and validity of the form in Turkish were performed by Çorapçığlu et al. ${ }^{11}$ The consistency rate for all diagnosis was calculated as $98.1 \%$ and the Kappa coefficient as 0.86 .

\section{Y-BOCS}

Y-BOCS, which consists of 19 items, was developed by Goodman et al to measure the type and severity of obsessive compulsive symptoms. ${ }^{12}$ It is administered by the interviewer. Only the first 10 items (except items $1 \mathrm{~b}$ and $6 \mathrm{~b}$ ) are used to determine the total points. Each question is answered on a Likert-type scale of 0-4 points. The Y-BOCS also includes a Symptom Control List and two subscales which measure the obsession severity (Y-BOCSo) and compulsion severity (Y-BOCSc). It was assessed for validity and reliability in Turkish by Karamustafaoğlu et al. The Chronbach $\alpha$ coefficient was reported as $0.81 .{ }^{13}$

\section{MCQ-30}

The MCQ-30 was developed by Wells and Cartwright-Hatton. ${ }^{14}$ The scale consists of 5 sub-scales each including 6 items: 1) positive beliefs about worry (MCQpb), 2) uncontrollability and danger (MCQud), 3) cognitive confidence (MCQcc), 4) need for controlling thoughts (MCQct), and 5) cognitive self-consciousness (MCQcs). The total 30 items are scored on a 4-point Likert-type scale. Higher points indicate metacognitive activity in a pathological form. Conformity of the MCQ-30 to Turkish was applied by Tosun and Irak. ${ }^{15}$ As a result of the analysis of the reliability of the scale, the Cronbach $\alpha$ value was between 0.72 and 0.93 for the sub-scales. In addition, the Cronbach $\alpha$ coefficient for the whole scale is $0.86 .^{15}$

\section{ATQ}

This scale was developed by Hollon and Kendall to measure the frequency of the occurrence of negative automatic thoughts directed at oneself. ${ }^{16}$ It is a 5-point Likert-type scale of 30 items. In the original scale, the points range from 30 to 150 . The level of the total points obtained in the scale indicates the frequency of the occurrence of automatic thoughts. The ATQ was translated and assessed for validity and reliability in Turkish by Şahin and Şahin. Cronbach $\alpha$ internal consistency coefficient of Turkish scale was 0.93 ; it was observed that the item total correlation of each scale item changed between 0.35 and $0.69 .{ }^{17}$

\section{$\mathrm{BDI}$}

The BDI is a scale consisting of 21 items, which was developed by Beck et al. ${ }^{18}$ Each item is scored between 0 and 3 . In a study of validity and reliability of the scale in Turkish, 
the cut-off point was defined as 17. Conformity of the BDI to Turkish was applied by Hisli. The Cronbach $\alpha$ coefficient was reported as $0.80 .^{19}$

\section{BAI}

The BAI measures the frequency and severity of symptoms of anxiety. It is a self-reported form of 21 items scored as a Likert-type scale of $0-3$ points. Higher total points indicate higher levels of anxiety. It was developed by Beck et $\mathrm{al}^{20}$ and assessed for validity and reliability in Turkish by Ulusoy et al. The Cronbach $\alpha$ coefficient was reported as $0.93 .^{21}$

\section{Statistical analysis}

All statistical evaluations were made using SPSS 22.0 (SPSS Inc., Chicago, IL, USA). Conformity of the data to normal distribution was assessed with the Shapiro-Wilk test. For variables showing normal distribution, one-way analysis of variance was applied and where a difference emerged, the origin of the difference was determined with least significant difference analysis. The Kruskal-Wallis test was applied to variables not showing normal distribution and where a difference emerged, the origin of the difference was determined with Bonferroni analysis. Chi-square analysis was applied to categorical variables. A value of $p<0.05$ was accepted as statistically significant.

\section{Results}

A statistically significant difference was determined between the genders of the participants. In the male subjects, there was determined to be a statistically significantly higher rate of autogenous obsession. The majority of the participants lived in a city. No significant difference was determined between the 3 groups in respect of marital status, income level, employment status and level of education. No statistically significant difference was determined between the AG and $\mathrm{RG}$ in respect of age at onset of the disease and duration of the disease (Table 1).

The differences between the scale points of the participants were examined with the Kruskal-Wallis test and all were found to be statistically significant $(p<0.001)$. The MCQ-30 and subscales, MCQud, MCQcc, MCQct and ATQ scale points were seen to be significantly higher in the AG

Table I Comparison of sociodemographic and clinical characteristics of the autogenous, reactive and control groups

\begin{tabular}{|c|c|c|c|c|c|}
\hline & Control n (\%) & Reactive n (\%) & Autogenous n (\%) & Post-hoc & $p$-value \\
\hline \multicolumn{5}{|l|}{ Gender n (\%) } & $0.020 *$ \\
\hline Male & $49(36.8)$ & $19(25.7)$ & $29(49.2)$ & $2 / 3$ & \\
\hline Female & $84(63.2)$ & $55(74.3)$ & $30(50.8)$ & $2 / 3$ & \\
\hline \multicolumn{5}{|l|}{ Occupation n (\%) } & 0.140 \\
\hline Unemployed & $23(17.3)$ & $24(32.4)$ & $17(28.8)$ & & \\
\hline Employed & $52(39.1)$ & $17(23.0)$ & $19(32.2)$ & & \\
\hline Retired & $5(3.8)$ & $3(4.1)$ & $3(5.1)$ & & \\
\hline Student & $53(39.8)$ & $30(40.5)$ & $20(33.9)$ & & \\
\hline \multicolumn{5}{|l|}{ Income level n (\%) } & 0.593 \\
\hline Below minimum wage & $87(65.4)$ & $53(71.6)$ & $38(64.4)$ & & \\
\hline Above minimum wage & $46(34.6)$ & $21(28.4)$ & $21(35.6)$ & & \\
\hline \multicolumn{5}{|l|}{ Marital status n (\%) } & 0.598 \\
\hline Single & $74(55.6)$ & $45(60.8)$ & $37(62.7)$ & & \\
\hline Married & $59(44.4)$ & $29(39.2)$ & $22(37.3)$ & & \\
\hline \multicolumn{5}{|c|}{ Place of residence $n(\%)$} & $0.001 *$ \\
\hline Village & $14(10.5)$ & $21(28.4)$ & $18(30.5)$ & $\mathrm{I} / 2.3$ & \\
\hline City & $119(89.5)$ & $53(71.6)$ & $4 \mathrm{I}(69.5)$ & $1 / 2.3$ & \\
\hline \multicolumn{5}{|l|}{ Age (years) } & 0.988 \\
\hline $\bar{x} \pm s d$ & $31.18 \pm 12.9$ & $30.96 \pm 12.1$ & $31.49 \pm 14.3$ & & \\
\hline Median (25\%-75\%) & $26(2 I-40)$ & $26(20-40)$ & $26(20-38)$ & & \\
\hline \multicolumn{5}{|l|}{ Years of education } & 0.440 \\
\hline $\bar{x} \pm s d$ & 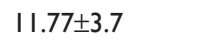 & $11.36 \pm 3.6$ & $12 \pm 3.7$ & & \\
\hline Median (25\%-75\%) & $12(11-15)$ & $12(10.75-14)$ & $13(1 \mid-15)$ & & \\
\hline \multicolumn{5}{|c|}{ Age at onset of disease (years) } & 0.688 \\
\hline $\bar{x} \pm s d$ & - & $21.7 \pm 10.3$ & $21.48 \pm 11.9$ & & \\
\hline \multicolumn{2}{|l|}{ Median (25\%-75\%) } & $17.5(15-27.25)$ & $18(14-27)$ & & \\
\hline \multicolumn{4}{|c|}{ Disease duration (months) } & & 0.247 \\
\hline $\bar{x} \pm s d$ & - & $108.01 \pm 90.7$ & $122.42 \pm 86.3$ & & \\
\hline \multicolumn{2}{|l|}{ Median $(25 \%-75 \%)$} & $78(36-144)$ & $120(48-180)$ & & \\
\hline
\end{tabular}

Note: ${ }^{*} p<0.05$. 
Table 2 Comparison of the scale points of the autogenous, reactive and control groups

\begin{tabular}{|c|c|c|c|c|c|}
\hline & $\begin{array}{l}\text { Control } \\
\bar{x} \pm s d \\
\text { Median } \\
(25 \%-75 \%)\end{array}$ & $\begin{array}{l}\text { Reactive } \\
\bar{x} \pm s d \\
\text { Median } \\
(25 \%-75 \%)\end{array}$ & $\begin{array}{l}\text { Autogenous } \\
\bar{x} \pm s d \\
\text { Median } \\
(25 \%-75 \%)\end{array}$ & Post-hoc & $p$-value \\
\hline Y-BOCS & $0.74 \pm 1.4$ & $26.85 \pm 8.3$ & $28.24 \pm 8.7$ & $1 / 2.3$ & $<0.001$ \\
\hline Total & $0(0-1)$ & $28(21.5-33)$ & $28(2 \mathrm{I}-36)$ & & \\
\hline Y-BOCS & $0.42 \pm 0.8$ & $|3.54 \pm 4|$. & $15.37 \pm 4.5$ & $1 / 2.3$ & $<0.001$ \\
\hline Obsessions & $0(0-1)$ & $14(10-16)$ & $16(13-20)$ & & \\
\hline Y-BOCS & $0.39 \pm 0.8$ & $13.18 \pm 4.3$ & $12.83 \pm 5.2$ & $\mathrm{I} / 2.3$ & $<0.001$ \\
\hline Compulsions & $0(0-0)$ & $13(10-16)$ & $13(9-18)$ & & \\
\hline MCQ & $53.36 \pm 9.7$ & $76.5 I \pm I 5.8$ & $83.4 I \pm I 4.6$ & $1 / 2 / 3$ & $<0.001$ \\
\hline Total & $52(4 \mid .5-63.5)$ & $76(66.75-87.25)$ & $88(78-95)$ & & \\
\hline MCQ & $9.68 \pm 3.6$ & $13.12 \pm 4.6$ & $12.10 \pm 5.3$ & $1 / 2.3$ & $<0.001$ \\
\hline Positive beliefs about worry & $9(6-12)$ & $12(10-16.25)$ & II (7-16) & & \\
\hline MCQ & $10.80 \pm 3.9$ & $16.31 \pm 3.8$ & $18.76 \pm 4.0$ & $1 / 2 / 3$ & $<0.001$ \\
\hline \multicolumn{6}{|l|}{ uncontrollability and danger } \\
\hline MCQ & $10.60 \pm 3.9$ & $13.96 \pm 5.2$ & $15.80 \pm 5.04$ & $1 / 2 / 3$ & $<0.001$ \\
\hline Lack of cognitive confidence & $10(7-13)$ & $13(10-18)$ & $16(12-19)$ & & \\
\hline MCQ & $10.62 \pm 3.8$ & $16.43 \pm 4.6$ & $19.07 \pm 36$ & $1 / 2 / 3$ & $<0.001$ \\
\hline Need to control thoughts & $10(7.5-13)$ & $17(13-20)$ & $19(17-22)$ & & \\
\hline MCQ & $1 \mathrm{I} .80 \pm 4.5$ & $16.85 \pm 3.8$ & $18.02 \pm 2.9$ & $1 / 2.3$ & $<0.001$ \\
\hline Cognitive self-consciousness & II (8-16) & $18(14-19)$ & $18(16-20)$ & & \\
\hline \multirow[t]{2}{*}{ ATQ } & $46.87 \pm 15.3$ & $62.31 \pm 21.0$ & $76.66 \pm 26.8$ & $1 / 2 / 3$ & $<0.001$ \\
\hline & $43(36-52)$ & $63(44.75-75)$ & $84(54-95)$ & & \\
\hline \multirow[t]{2}{*}{ BDI } & $2.59 \pm 3.5$ & $12.01 \pm 7.4$ & $14.07 \pm 7.6$ & $1 / 2.3$ & $<0.001$ \\
\hline & I (0-4) & II (7-16) & $13(9-20)$ & & \\
\hline \multirow[t]{2}{*}{ BAI } & $2.62 \pm 4.0$ & $|3.99 \pm| 1.4$ & $17.47 \pm 12.7$ & $1 / 2.3$ & $<0.001$ \\
\hline & $0(0-4.5)$ & $10(4-20)$ & $14(8-22)$ & & \\
\hline
\end{tabular}

Abbreviations: ATQ, Automatic Thoughts Questionnaire; BAI, Beck Anxiety Inventory; BDI, Beck Depression Inventory; MCQ, Metacognition Questionnaire; Y-BOCS, Yale-Brown Obsessive Compulsive Scale.

than in the RG and significantly higher in the RG than in the control group (Table 2).

In the $\mathrm{RG}$, a weak correlation was determined between the MCQ-30 points and the YBOCSo (obsession subscale) points, and a moderate level correlation between the MCQ-30 points and the ATQ, BDI and BAI points. A moderate level correlation was determined between the ATQ, and BDI and BAI points. In the $\mathrm{AG}$, a weak correlation was determined between the MCQ-30 points and the Y-BOCS, Y-BOCSo, Y-BOCSc and BAI points. A moderate level correlation was determined between the ATQ, and BDI and BAI points (Table 3).

To separately determine the predictive values of the ATQ points in the autogenous obsession group and the reactive obsession group, multiple linear regression analysis was applied to the YBOCS, MCQ-30, BDI and BAI points. In the reactive obsession group, the predictive variables of the ATQ points were determined to be MCQ-30, BDI and BAI. In the autogenous obsession group, the predictive

Table 3 Correlations of the MCQ scale points with the other scale points

\begin{tabular}{|c|c|c|c|c|c|c|}
\hline & Y-BOCS & Y-BOCSo & Y-BOCSc & ATQ & BDI & BAI \\
\hline \multicolumn{7}{|c|}{ Reactive group } \\
\hline MCQ-30 & 0.216 & $0.25 \mathrm{I}^{\mathrm{a}}$ & 0.228 & $0.50 \mathrm{I}^{\mathrm{b}}$ & $0.467^{\mathrm{b}}$ & $0.477^{\mathrm{b}}$ \\
\hline \multicolumn{7}{|l|}{ Rho } \\
\hline ATQ & 0.210 & 0.216 & 0.193 & I & $0.529^{b}$ & $0.519^{\circ}$ \\
\hline \multicolumn{7}{|c|}{ Autogenous group } \\
\hline MCQ-30 & $0.330^{\mathrm{a}}$ & $0.300^{\mathrm{a}}$ & $0.315^{\mathrm{a}}$ & 0.113 & 0.206 & $0.278^{a}$ \\
\hline \multicolumn{7}{|l|}{ Rho } \\
\hline ATQ & 0.087 & 0.151 & 0.028 & I & $0.532^{\mathrm{b}}$ & $0.422^{\mathrm{b}}$ \\
\hline
\end{tabular}

Notes: ${ }^{a} p<0.05 ;{ }^{b} p<0.01$.

Abbreviations: ATQ, Automatic Thoughts Questionnaire; BAI, Beck Anxiety Inventory; BDI, Beck Depression Inventory; MCQ, Metacognition Questionnaire; Y-BOCS, Yale-Brown Obsessive Compulsive Scale. 
Table 4 Results of regression analysis (predictive values of the ATQ)

\begin{tabular}{lllllll}
\hline $\begin{array}{l}\text { Predicted } \\
\text { variable: ATQ }\end{array}$ & $\begin{array}{l}\text { Predictive } \\
\text { variable }\end{array}$ & Beta & t & R & $\mathbf{R}^{2}$ & F \\
\hline Reactive group & Y-BOCS & 0.043 & 0.457 & 0.652 & 0.425 & $12.737^{\mathrm{b}}$ \\
& MCQ-30 & 0.261 & $2.467^{\mathrm{a}}$ & & & \\
& $\mathrm{BDI}$ & 0.224 & $2.029^{\mathrm{a}}$ & & & \\
Autogenous & $\mathrm{BAI}$ & 0.312 & $2.789^{\mathrm{a}}$ & & & \\
group & Y-BOCS & -0.197 & -1.574 & 0.624 & 0.389 & $8.613^{\mathrm{b}}$ \\
& $\mathrm{MCQ}-30$ & 0.124 & 1.034 & & & \\
& $\mathrm{BDI}$ & 0.529 & $4.414^{\mathrm{b}}$ & & & \\
& $\mathrm{BAI}$ & 0.236 & $2.065^{\mathrm{a}}$ & & & \\
\hline
\end{tabular}

Notes: ${ }^{a} p<0.05 ;{ }^{b} p<0.01$.

Abbreviations: ATQ, Automatic Thoughts Questionnaire; BAl, Beck Anxiety Inventory; BDI, Beck Depression Inventory; MCQ-30, Metacognition Questionnaire30; Y-BOCS, Yale-Brown Obsessive Compulsive Scale.

variables of the ATQ points were determined to be BDI and BAI (Table 4).

\section{Discussion}

As OCD has a heterogenous structure, the identification of homogenous sub-groups is important to be able to understand the pathophysiology of these patients and to be aware of differences in responses to treatment.

The results of the current study showed no statistically significant difference between the AG, RG and control groups in respect of age, level of education, employment status, marital status, income level, age at onset of disease, duration of disease. Similarly, Belloch et al found no significant difference between $A G$ and $R G$ in respect of age, marital status, income level and education. ${ }^{22}$ Besiroğlu et al also found no significant difference between $A G$ and $R G$ in respect of mean age and level of education. ${ }^{23}$ In another study by Besiroğlu et al the age at onset of the disease was reported to be older in the AG compared to the reactive and mixed groups. ${ }^{24}$ Conversely, Subira et al reported the age at onset of the disease to be significantly younger in the AG compared to the RG. ${ }^{25}$ In another study of OCD patients which was similar to the current study, no difference was determined between the AG and RG in respect of the mean duration of the disease. ${ }^{26}$ In the current study, there was high degree of similarity in the sociodemographic and clinical characteristics of the AG and RG. This provided the possibility of a more objective comparison in terms of the scale points and correlations between the groups.

When examined in terms of gender, the number of male patients in the AG of the current study was statistically significantly greater. This finding was consistent with that of a study of 177 patients by Besiroğlu et al in which there were determined to be more male patients in the AG. ${ }^{24}$ There are also studies in literature in which no significant gender difference has been determined between AG and RG. ${ }^{23,25,26}$

The mean BDI and BAI points were similar in the AG and RG of the current study. In a study by Lee et al while there was similarly no significant difference between the AG and $\mathrm{RG}$, the mean BDI points of both groups were reported to be significantly higher than those of the control group. ${ }^{27,28}$ The MCQ-30, MCQud, MCQcc, MCQct and ATQ points were seen to be statistically higher in the AG than in the RG and in the RG than in the control group. In a study by Doğan et al metacognitions were compared in OCD sub-types and a healthy control group, no statistically significant difference was observed between the AG and RG in any of the MCQ-30 sub-scales or the total points. The probable reason that no difference was observed was the small sample size compared with that of the current study. ${ }^{29}$ Moritz et al reported that the high level of negative beliefs about uncontrollability and danger (MCQud) sub-scale could be related to the severity of the obsessions. ${ }^{9}$ Tosun and Irak and showed that obsessive compulsive symptoms and continuous anxiety were independently strongly predictive of metacognition beliefs, especially related to the dimension of uncontrollability and danger. ${ }^{15}$ In a study by Sica et al findings were obtained that anxiety and obsessive compulsive symptoms were predictive of the uncontrollability and danger dimension. ${ }^{30}$ There are other studies showing that OCD symptoms are markers of the need to control thoughts. ${ }^{31,32}$

This view is supported in the study by Irak and Tosun, which reported that obsessive compulsive symptoms are the basic metacognitive factor of the need to control thoughts. ${ }^{33}$ Individuals with autogenous obsessions have a tendency to perceive thoughts as irrational and foreign to themselves and suppress these or frequently use coverage control strategies. ${ }^{2,34}$ The need to control thoughts includes superstitions, punishment and the need to control negative thoughts, including the themes of responsibility. ${ }^{15}$ For example, if a person has an intrusive thought that he is going to harm his family members, it is possible he/she thinks that the intrusive thought is a part of his/her nature, and to be controlled in some way (eg, thought stopping, distraction), whereas reactive obsessions appeared to bring out more behavioral control strategies (eg, excessive acting such as checking). ${ }^{34}$ When the individual cannot control these, these beliefs are related to the view that the individual is responsible for the harmful results that occur and will be punished. This could explain the high level of MCQud and MCQct in the AG.

Cognitive theory suggests that the anxiety and depression of psychological disorders are maintained by a "thought 
disorder" accompanied by thought distortions expressed through negative automatic thoughts. In depression, these thoughts reflect a negative view about the self, the world and the future, whereas in anxiety, they reflect a subject of danger and a negligible ability to deal with it. ${ }^{8}$ When a negative belief is activated, it is thought that negative automatic thoughts emerge in the stream of consciousness. Negative automatic thoughts are considered to have a dysfunctional and maladjusted effect on the evaluation of the environment in which an individual finds themselves and in interpreting the relationship with themselves. ${ }^{35,36}$ In a study with nonclinical sampling, Corcoran and Woody obtained results that in evaluations of the thoughts of participants related to aggression, sexuality and sinfulness, they saw themselves as a bad and immoral person and these were related to obsessive compulsive symptoms. ${ }^{37}$ Previous studies have determined that autogenous obsessions aroused greater feelings of guilt than reactive obsessions. , $^{2,34}$

Guilt is a negative self-conscious emotion associated with negative outcomes or self-evaluations. ${ }^{38}$ In a non-clinical sample study by Seo and Seok, it was reported that individuals with autogenous obsessions tend to focus on the obsessions and the meaning of having them has a greater tendency to make negative outcomes for themselves in the context of disturbing intrusive thoughts than those with reactive obsessions. The ego-dystonic, bizarre and threatening features of the autogenous obsessions bring out vulnerability to accept their obsessions as revealing negative characteristics of their nature. However, those with reactive obsessions pay more attention to external events rather than themselves. ${ }^{39}$ In our study, the anxiety, guilt and negative judgements formed by the negative images and intrusive thoughts coming into the mind of an individual with sexual or aggression obsession in the AG and people with autogenous obsessions tend to focus on the obsessions and the meaning of having them has a greater tendency to make negative outcomes for themselves could explain the significant elevation of negative automatic thoughts in the AG. Results obtained from studies of people without depression, suggested that an increased formation of automatic negative thoughts, as measured with the ATQ, increased vulnerability to the development of symptoms following a depressive trigger. ${ }^{40}$

In our study, moderate correlations of ATQ with BDI and BAI were found in both the AG and RG. In the reactive obsession group, there was a moderate level correlation between MCQ-30 and ATQ, but this correlation was not determined in the AG, also BDI, BAI and MCQ-30 were determined to be predictive of ATQ in the RG, and in the AG, BDI and
BAI were determined to be predictive of ATQ not MCQ-30. In a non-clinical sample study by Hjemdal et al, a positive significant correlation was determined between ATQ and MCQ-30. While there was a high level correlation between both anxiety and depressive symptoms and ATQ, the correlation with MCQ-30 was at a moderate level. It has been reported that ATQ predicts future depression but not anxiety, and MCQ-30 is predictive of the change in both depression and anxiety. ${ }^{41}$

While those with reactive obsessions are worried about the negative results of possible external events (negative events that could harm themselves or others, such as fatal contaminations or accidents), those with autogenous obsessions feel concerns about themselves when making inferences about obsessions. ${ }^{2}$ There is a close relationship between autogenous obsessions and schizotypal personality characteristics and reactive obsessions are more closely associated with uncertainty intolerance, responsibility and perfectionism. ${ }^{34}$ Lee et al reported that OCD patients showing autogenous obsessions have more severe perception distortions and irrational thoughts compared with those with reactive obsessions. ${ }^{42}$ In various perception/thought indexes of the Rorschach Ink Blot test, ${ }^{43}$ there has been found to be no difference between OCD patients with autogenous obsessions and schizophrenia patients. In contrast, no difference has been seen between OCD patients showing primarily reactive obsessions and non-psychotic patients such as those with other anxiety disorders. ${ }^{44}$ It has been suggested that thought disorder is more often encountered in those with autogenous obsession and they are more exposed to antipsychotic treatment. ${ }^{45,46}$ From a characteristic point of view, reactive obsessions are between worry and autogenous obsessions. ${ }^{44}$ The correlation between ATQ and MCQ-30 found in those with reactive obsessions, and that the finding that MCQ-30 is predictive of ATQ was not present in the AG, may be a result of the perception distortions and irrational thoughts of patients with autogenous obsessions, and the formation of the pathology is closer to a thought disorder rather than an anxiety disorder.

In anxiety disorders, automatic thoughts show the theme of danger and an underestimation of handling. ${ }^{8}$ Since the $\mathrm{RG}$ 's formation of the pathology is closer to an anxiety disorder rather than the $\mathrm{AG}$, the increase in automatic thoughts may lead to increase in underestimation of coping skills and the activation of metacognitive processes. Also, this may explain the correlation between ATQ and MCQ found in those with reactive obsessions and that the finding that MCQ is predictive of ATQ was not present in the AG. 
In the current study, differences were determined between the AG and the RG in respect of metacognitions and automatic thoughts. In the light of these results, the recommended grouping can be considered useful in the identification of OCD sub-types. No statistically significant differences were determined between the patient groups in this study in respect of clinical and sociodemographic characteristics. That the variables between the groups were similar and the groups were homogenous, provided more robust results by filtering out additional factors when comparing the data of the 2 groups.

There were some limitations to the study, primarily that a significant proportion of the patients were receiving psychiatric medical treatment during the study. The treatment could have had an effect on both the obsessive compulsive symptoms and the metacognitions and automatic thoughts. The lack of an adequate and clear instrument to fully define AG and RG could have had an effect on the evaluation of the results that were based on self-reporting in most of the scales. Another important limitation of the study is that it was cross-sectional and the patients were interviewed by a single researcher. It is thought that more interviewers and dimensional evaluation could have strengthened the results.

In conclusion, it can be said that there is a need for further studies to identify more homogenous sub-types of OCD, which has the clinical appearance of an extremely heterogenous nature. Future multi-center studies of sub-typing with larger samples using more specific instruments to sub-type and for dimensional evaluation will be useful for detailed evaluation and better understanding of the subject.

\section{Disclosure}

The authors report no conflicts of interest in this work.

\section{References}

1. American Psychiatric Association. Diagnostic and Statistical Manual of Mental Disorders. 4th ed. Washington DC: American Psychiatric Association; 2000.

2. Lee HJ, Kwon SM. Two different types of obsession: autogenous obsessions and reactive obsessions. Behav Res Ther. 2003;41(1):11-29.

3. Wells A, Papageorgiou C. Relationships between worry, obsessivecompulsive symptoms and meta-cognitive beliefs. Behav Res Ther. 1997; 36(9):899-913.

4. Wells A, Cartwright-Hatton S. A short form of the meta-cognitions questionnaire: properties of the MCQ 30. Behav Res Ther. 2004;42(4): 385-396.

5. Wells A, Mathews G. Modelling cognition in emotional disorder: the S-REF model. Behav Res Ther. 1996;34(11-12):881-888.

6. Gwilliam P, Wells A, Cartwright-Hatton S. Does meta-cognition or responsibility predict obsessive-compulsive symptoms? A test of the meta-cognitive model. Clin Psychol Psychother. 2004;11(2):137-144.

7. Beck AT. Cognitive Therapy and The Emotional Disorders. New York: International Universities Press; 1976.
8. Beck AT. Cognitive models of depression. J Cogn Psychother. 1987;1: 5-37.

9. Moritz S, Peters MJ, Laroi F, Lincoln TM. Metacognitive beliefs in obsessive-compulsive patients: a comparison with healthy and schizophrenia participants. Cogn Neuropsychiatry. 2010;15(6): 531-548.

10. First MB, Spitzer RL, Gibbon M. Structured Clinical Interview For DSM-IV Clinical Version (SCID-I/CV). Washington: American Psychiatric Press; 1997.

11. Çorapcıŏglu A, Aydemir O, Yıldız M. DSM-IV eksen 1 ruhsal bozukluklarına göre Türkçe yapılandırılmıs klinik değerlendirmenin güvenirliği [The reliability of the Turkish structured clinical evaluation according to DSM-IV axis 1 mental disorders]. Ilaç ve Tedavi Dergisi. 1999;12:33-36. Turkish.

12. Goodman WK, Price LH, Rasmussen SA, et al. The Yale-Brown Obsessive Compulsive Scale, I: Development, use and reliability. Arch Gen Psychiatry. 1989;46(11):1006-1011.

13. Karamustafalıoğlu KO, Üçışık AM, Ulusoy M. Yale-Brown ObsesyonKompulsiyon Derecelendirme Ölçeği'nin geçerlilik ve güvenilirlik çalışması [Validity and reliability study of Yale-Brown ObsessionCompulsion Rating Scale]. Bursa Savaş Press; 1993. Turkish.

14. Wells A, Cartwright-Hatton S. A short form of the metacognitions questionnaire: properties of the MCQ-30. Behav Res Ther. 2004;42(4): 385-396.

15. Tosun A, Irak M. Üstbiliş Ölçeği-30'un Türkçe uyarlaması, geçerliği, güvenirliği, kaygı ve obsesif-kompülsif belirtilerle ilişkisi [Turkish adaptation, validity, reliability, anxiety and relationship with the obsessive-compulsive symptoms]. Türk Psikiyatri Dergisi. 2008;19(1):67-80. Turkish.

16. Hollon S, Kendall P. Cognitive self-statement in depression: clinical validation of an automatic thoughts questionaire. Cognit Ther Res. 1980; 4(4):383-395.

17. Şahin NH, Şahin N. Reliability and validity of the Turkish version of the automatic thoughts questionnaire. J Clin Psychol. 1992;48(3): 334-340.

18. Beck AT, Ward CH, Mendelson M, Mock J, Erbaugh J. An inventory for measuring depression. Arch Gen Psychiatry. 1961;4:561-571.

19. Hisli N. Beck Depresyon Envanterinin üniversite öğrencileri için geçerliliği, güvenirliği [Validity, reliability of the Beck Depression Inventory for university students]. Psikoloji Dergisi. 1989;7:3-13. Turkish.

20. Beck AT, Epstein N, Brown G, Steer RA. An inventory for measuring clinical anxiety: Psychometric properties. J Consult Clin Psychol. 1988;56(6):893-897.

21. Ulusoy M, Sahin NH, Erkmen H. Turkish version of the Beck anxiety inventory: psychometric properties. J Cogn Psychother Int. 1998;12(2): 163-172.

22. Belloch A, Cabedo E, Carrio C, Larsson C. Cognitive therapy for autogenous and reactive obsessions: clinical and cognitive outcomes at post-treatment and 1-year follow-up. J Anxiety Disord. 2010;24(6): 573-580.

23. Besiroglu L, Sozen M, Ozbebit O, et al. The involvement of distinct neural systems in patients with obsessive-compulsive disorder with autogenous and reactive obsessions. Acta Psychiatr Scand. 2011; 124(2):141-151.

24. Besiroglu L, Agargun MY, Ozbebit O, Aydin A. A discrimination based on autogenous versus reactive obsessions in obsessive compulsive disorder and related clinical manifestations. CNS Spectr. 2006;11(13): 179-186.

25. Subira $\mathrm{M}$, Alonso $\mathrm{P}$, Segalàs $\mathrm{C}$, et al. Brain structural alterations in obsessive-compulsive disorder patients with autogenous and reactive obsessions. PLoS One. 2013;8(9):e75273.

26. Besiroglu L, Uğuz F, Sağlam M, Ağargün MY, Aşkın R, Çilli A. Otojen ve Reaktif Obsesyonlara Sahip Obsesif Kompulsif Hastalarda Psikofarmakolojik Tedaviye Yanıt [Responses to Psychopharmacologic Treatment in Obsessive Compulsive Patients with Autogenous and Reactive Obsessions]. Klinik Psikofarmakol Bülteni. 2007;17(1):1-8. Turkish. 
27. Lee HJ, Yost BP, Telch MJ. Differential performance on the go/no-go task as a function of the autogenousereactive taxonomy of obsessions: findings from a on-treatment seeking sample. Behav Res Ther. 2009; 47(4):294-300.

28. Lee HJ, Telch MJ. Differences in latent inhibition as a function of the autogenous reactive OCD subtype. Behav Res Ther. 2010;48(7): $571-579$.

29. Doğan K, Solak Ö, Özdel K, Türkçapar MH. Obsesif Kompulsif Bozukluk Alt Tiplerinde ve Sağlıklı Kontrol Grubunda Üstbilișlerin Karşılaştırılması [Comparison of Metacognition in Obsessive Compulsive Disorder Subtypes and Right Control Group]. Bilişsel Davranışçı Psikoterapi ve Araştırmalar Dergisi. 2013;2:34-40. Turkish.

30. Sica C, Steketee G, Ghisi M, Chiri LR, Franceschini S. Metacognitive beliefs and strategies predict worry, obsessive-compulsive symptoms and coping styles: a preliminary prospective study on an Italian nonclinical sample. Clin Psychol Psychother. 2007;14(4):258-268.

31. Myers SG, Wells A. Obsessive-compulsive symptoms: the contribution of metacognitions and responsibility. J Anxiety Disord. 2005;19(7): 806-817.

32. Clark DA, Purdon CL. The assessment of unwanted intrusive thoughts: a review and critique of the literature. Behav Res Ther. 1995;33(8): 967-976.

33. Irak M, Tosun A. Exploring the role of the meta-cognition in obsessivecompulsive and anxiety symptoms. J Anxiety Disord. 2008;22(8): 1316-1325.

34. Lee HJ, Telch MJ. Autogenous/reactive obsessions and their relationship with OCD symptoms and schizotypal personality features. J Anxiety Disord. 2005;19(7):793-805.

35. Beck AT, Brown G, Steer RA, Eidelson JI, Riskind JH. Differentiating anxiety and depression: A test of the cognitive content specificity hypothesis. J Abnorm Psychol. 1987;96(3):179-183.

36. Beck AT, Emery G, Greenberg RL. Anxiety Disorders and Phobias: A Cognitive Perspective. New York: Basic Books; 1985.
37. Corcoran KM, Woody SR. Appraisals of obsessional thoughts in normal samples. Behav Res Ther. 2008;46(1):71-83.

38. Leary MR. Motivational and emotional aspects of the self. Annu Rev Psychol. 2007;58:317-344.

39. Seo JW, Seok MK. Autogenous/reactive obsessions and their relationship with negative self-inferences. J Obsessive Compuls Relat Disord. 2013;2(3):316-321.

40. Stiles TC, Göestam KG. The role of automatic negative thoughts in the development of dysphoric mood: an analogue experiment. Cognit Ther Res. 1989;13(2):161-170.

41. Hjemdal O, Stiles T, Wells A. Automatic thoughts and meta-cognition as predictors of depressive or anxious symptoms: a prospective study of two trajectories. Scand J Psychol. 2013;54(2):59-65.

42. Lee HJ, Kim ZS, Kwon SM. Thought disorder in patients with obsessive compulsive disorder. J Clin Psychol. 2005;61(4):401-413.

43. Exner JE. The Rorschach: A Comprehensive System. Vol. I: Basic Foundations. 3rd ed. New York: Wiley; 1993.

44. Lee HJ, Lee SH, Kim HS, Kwon SM, Telch MJ. A comparison of autogenous/reactive obsessions and worry in a non-clinical population: a test of the continuum hypothesis. Behav Res Ther. 2005;43: 999-1010.

45. Çamlı K, Türkçapar MH, Sargın AE. Reaktif ve otojen özellik gösteren obsesif kompulsif bozuklıkta içgörü bilsssel işgörü ve sosyodemografik özellikler [Cognitive insight and sociodemographic characteristics in obsessive compulsive disorder with reactive and autogenous features]. Bilişsel Davranış̧̧ı Psikoterapi ve Araștırmalar Dergisi. 2012;1:28-35. Turkish.

46. Batmaz S, Yildiz M, Songur E. Psychopharmacological treatment differences in autogenous and reactive obsessions: a retrospective chart review. Nord J Psychiatry. 2016;70(1):31-37.
Neuropsychiatric Disease and Treatment

\section{Publish your work in this journal}

Neuropsychiatric Disease and Treatment is an international, peerreviewed journal of clinical therapeutics and pharmacology focusing on concise rapid reporting of clinical or pre-clinical studies on a range of neuropsychiatric and neurological disorders. This journal is indexed on PubMed Central, the 'PsycINFO' database and CAS,

\section{Dovepress}

and is the official journal of The International Neuropsychiatric Association (INA). The manuscript management system is completely online and includes a very quick and fair peer-review system, which is all easy to use. Visit http://www.dovepress.com/testimonials.php to read real quotes from published authors. 